\title{
A Combined Theoretical and Experimental Study of Sarin (GB) Decomposition at High Temperatures
}

\author{
Xiao Shan, ${ }^{* \dagger \odot}$ Jack C. Vincent, ${ }^{\ddagger}$ Sue Kirkpatrick, ${ }^{\ddagger}$ Maurice D. Walker, ${ }^{\ddagger}$ Mark R. Sambrook, \\ and David C. Clary ${ }^{\dagger}$ \\ ${ }^{\dagger}$ Physical and Theoretical Chemistry Laboratory, Department of Chemistry, University of Oxford, South Parks Road, Oxford OX1 \\ 3QZ, United Kingdom \\ *CBR Division, DSTL Porton Down, Salisbury SP4 0JQ, United Kingdom
}

\section{Supporting Information}

ABSTRACT: Theoretical and experimental results are presented for the pyrolytic decomposition of the nerve agent sarin (GB) in the gas phase. High-level quantum chemistry calculations are performed together with a semiclassical transition-state theory for describing quantum mechanical tunneling. The experimental and theoretical results for the temperature dependence of the survival times show very good agreement, as does the calculated and measured activation energy for thermal decomposition. The combined results suggest that the thermal decomposition of $\mathrm{GB}$, for temperature ranging from 350 to $500{ }^{\circ} \mathrm{C}$, goes through a pericyclic reaction mechanism with a transition state consisting of a six-membered ring structure.

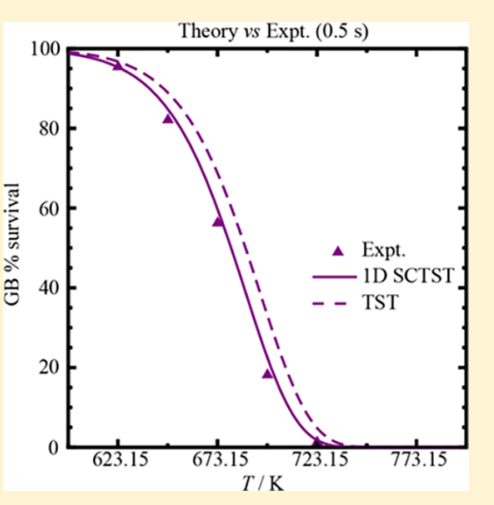

\section{INTRODUCTION}

The organophosphorus (OP) chemical warfare agent (CWA) isopropyl methylphosphonofluoridate, also known as sarin and $\mathrm{GB}$, is a highly toxic nerve agent that acts via the inhibition of acetylcholine esterase. ${ }^{1}$ The development and historical use of CWAs is well-documented, ${ }^{2}$ along with strategies for the breakdown and destruction. ${ }^{1,3}$ Although banned under the Chemical Weapons Convention the threat posed by the presence and use of GB and related CWA materials remains, as illustrated by events in the 1980s and 1990s in Iraq $^{4}$ and Japan $^{5,6}$ and more recently in Syria. ${ }^{7,8}$ Studies of the properties of GB and remediation of its presence as a contaminant therefore remain an active area of research. ${ }^{9-15}$ Various detoxification methods such as hydrolysis, biomimetic catalysis, photocatalysis, metal-catalyzed decomposition, and reduction have been studied both experimentally and theoretically in the past. $3,10,16-19$

Alternatively, pyrolysis and combustion can also be possible routes to the destruction of $\mathrm{GB}$, for example, by incineration, and increasingly detailed knowledge and understanding of the kinetics and mechanisms behind such approaches is valuable in implementation and validation. Work by Zegers and Fisher ${ }^{20}$ investigated the gas-phase pyrolysis of the commonly used CWA simulant diisopropyl methylphosphonate (DIMP) in a gas-flow reactor at $700-800 \mathrm{~K}$ and under timescales of 15 to 90 ms. Unimolecular decomposition to form isopropyl methylphosphonate and methylphosphonic acid was identified with an activation energy $E_{\mathrm{a}}$ of $153.55( \pm 20.50) \mathrm{kJ} / \mathrm{mol}$ determined. More recently, Glaude et al. ${ }^{21}$ have reported calculated reaction mechanisms for the degradation of GB, DIMP, dimethyl methylphosphonate (DMMP), and trimethyl phosphate (TMP) under simulated incineration conditions (natural gas $94 \%$ methane, $6 \%$ ethane) of 1 atm pressure, $1500 \mathrm{~K}$, and a residence time of $0.1 \mathrm{~s}$. In the case of $\mathrm{GB}$ the first reaction identified is a six-center elimination of propene and is stated as being the only reaction controlling the quantity of GB present in the reactor. Ash et al. ${ }^{22}$ have investigated the mechanism and kinetics of the gas-phase unimolecular isomerization and breakdown of GB and pinacolyl methylphosphonofluoridate (soman, or GD) over the temperature range of 300-1000 K using computational methods. The most favorable decomposition route identified for the decomposition of $\mathrm{GB}$ in this study is again via the formation of a six-membered transition state (TS) with calculated activation energy of $163.6 \mathrm{~kJ} / \mathrm{mol}$.

Herein we report combined experimental and computational study of the unimolecular gas-phase thermal degradation of GB. A tube furnace (TF) gas-flow reactor is used to expose GB vapor to temperatures in the range of $350-500{ }^{\circ} \mathrm{C}$ (ca. $623-$ $773 \mathrm{~K}$ ) and for residence times of $0.062-0.5 \mathrm{~s}$. Measured survival data and the estimated activation energy are compared to those obtained in quantum chemistry calculations. The thermochemical analysis is performed at MP2/aug-cc-pVTZ// $\operatorname{CCSD}(\mathrm{T}) / \mathrm{CBS}$ level of theory. The kinetic study of the microcanonical rate constant is performed using Rice-

Received: May 5, 2017

Revised: July 13, 2017

Published: July 13, 2017 
Ramsperger-Kassel-Marcus (RRKM) theory ${ }^{23}$ with tunneling probability calculated using one-dimensional semiclassical transition-state theory (1D SCTST). ${ }^{24,25}$ The 1D SCTST macrocanonical rate constant with the hindered rotor partition function corrections ${ }^{26-29}$ is calculated to compare directly to our experimental results.

The remainder of the article is organized as follows. Section 2 discusses the methods employed to calculate rate constants. Section 3 presents the computational and experimental details in the present work. Results of geometry optimizations, vibrational analyses, as well as reaction rate constant calculations are shown and discussed in Section 4. Finally, Section 5 summarizes the key findings of this study.

\section{THEORETICAL BACKGROUND}

2.1. Overview. In a semiclassical transition-state theory (SCTST), the reaction probabilities are directly calculated from the harmonic frequencies and anharmonic constants of the transition state (TS). ${ }^{24,25,30-41}$ The calculation of anharmonic constants requires higher than second-order derivatives $^{24,25,33-39}$ of the potential energy surface (PES) at the structures of interest, the TS, or the minima. One commonly employed theory is the second-order vibrational perturbation theory (VPT2), which requires the third and fourth order derivatives of the PES with respect to the normal mode coordinates. $^{24,25,33-38,42}$ Detailed derivations of the anharmonic constants as well as the SCTST can be found in refs 25 and 33.

A full-dimensional SCTST calculation for molecule as large as GB, which consists of in total 18 atoms and 48 internal degrees of freedom (DoFs) or vibrational normal modes, can be computationally expensive. In addition, some of the vibrations in such a large molecule may consist of mainly the movements of atoms that are not directly involved in the bond forming and breaking during a reaction. These modes are likely to be weakly coupled to the reaction mode. Treating them anharmonically would have very little effect on the overall reaction rate constant. We, therefore, employ the $1 \mathrm{D}$ SCTST $^{24,25}$ in the current study. A brief outline of this theory is given here; detailed discussion can be found elsewhere. ${ }^{24,25}$

2.2. 1D SCTST. In a $1 D$ SCTST calculation, ${ }^{25}$ we only treat the reaction mode of the TS anharmonically. The remaining $(3 N-6-1)$ spectator modes of the TS are all treated harmonically. In addition, the spectator modes are assumed not to couple with the reaction mode in such a way that the third and fourth order derivatives of the PES with respect to spectator modes are assumed to be 0 . The reaction mode anharmonic constant is then given by ${ }^{25,32,42}$

$$
x_{\mathrm{FF}}=\frac{\hbar^{2}}{16{\omega_{\mathrm{F}}}^{2}}\left(f_{\mathrm{FFFF}}-\frac{5 f_{\mathrm{FFF}}^{2}}{3{\omega_{\mathrm{F}}^{2}}^{2}}\right)
$$

where the subscript $\mathrm{F}$ denotes the reaction mode, $\omega_{\mathrm{F}}$ is the reaction mode frequency, and $f_{\mathrm{FFF}}$ and $f_{\mathrm{FFFF}}$ are the third and fourth order derivatives of the PES with respect to the reaction mode, respectively. In the VPT2 treatment, a constant energy parameter, $G_{0}$, should be added to the harmonic adiabatic reaction energy barrier. Its $1 \mathrm{D}$ form is given by ${ }^{25,33}$

$$
G_{0}=\frac{\hbar^{2}}{64}\left(\frac{f_{\mathrm{FFFF}}}{\omega_{\mathrm{F}}^{2}}-\frac{5}{9} \frac{f_{\mathrm{FFF}}{ }^{2}}{\omega_{\mathrm{F}}{ }^{4}}\right)
$$

In the $1 \mathrm{D}$ treatment, the effective reaction mode frequency is independent of the quantum numbers of the spectator modes: ${ }^{25}$

$$
\Omega=\operatorname{Im}\left(\hbar \omega_{\mathrm{F}}\right)
$$

The barrier penetration integral is then calculated according to WKB theory: ${ }^{43}$

$$
\theta\left(E_{\mathrm{v}}\right)=\pi \frac{-\Omega+\left[\Omega^{2}+4 x_{\mathrm{FF}}\left(\Delta V_{f}+G_{0}-E_{\mathrm{v}}\right)\right]^{1 / 2}}{2 x_{\mathrm{FF}}}
$$

Since the spectator mode configuration is not included in the effective reaction mode frequency, in 1D SCTST, the cumulative reaction probability (CRP) $N\left(E_{\mathrm{v}}\right)$ is the same as $P\left(E_{\mathrm{v}}\right)$, which is given by

$$
P\left(E_{\mathrm{v}}\right)=\left\{1+\exp \left[2 \theta\left(E_{\mathrm{v}}\right)\right]\right\}^{-1}
$$

In our previous studies, we found that the deep tunneling (DT) corrections proposed by Wagner ${ }^{44}$ should be included in a 1D SCTST calculation. In this correction, the potential energy barrier is modeled as a piecewise asymmetric Eckart potential, so that the tunneling is allowed at all energies greater than the threshold energy:

$$
E_{\text {thresh }}=\max \left(\Delta V_{\mathrm{f}}-\Delta V_{\mathrm{r}}, 0\right)
$$

where $\Delta V_{\mathrm{r}}$ is the adiabatic reverse barrier height. The exact treatment can be found in refs 24,25 , and 44 . We note that the DT correction requires the information of the reverse barrier height, which brings a small amount of additional computational cost to the standard SCTST calculation, but the improvement on the resulting rate constant can be significant. It is also included in the current study.

2.3. Richardson Extrapolation. In a previous study, ${ }^{25}$ we applied the Richardson extrapolation method ${ }^{45-47}$ to improve the accuracy of numerical derivatives of the PES. Briefly, we denote $A(x)$ and $A(m x)$ the two numerical derivatives calculated with step sizes $x$ and $m x$ with $m>1$, respectively. They can be combined in the following way to estimate the derivative with smaller error:

$$
B(x)=\frac{m^{2} A(x)-A(m x)}{m^{2}-1}
$$

$B(x)$ is a "first-order extrapolation" of the derivative. Similar procedure can be applied to two first-order extrapolations to yield a "second-order extrapolation" with even smaller error:

$$
C(x)=\frac{m^{4} B(x)-B(m x)}{m^{4}-1}
$$

To compute $C(x)$, one needs zeroth-order derivatives at three different step sizes. This approach can, in principle, be applied multiple times to yield a higher-order extrapolation with very small error. In our previous study, ${ }^{25}$ extrapolation to the order of 3 is often sufficiently accurate.

2.4. Rate Constants. The microcanonical rate constant can be written as: ${ }^{23}$

$$
k\left(E_{\mathrm{v}}\right)=\frac{1}{h} \frac{G^{\ddagger}\left(E_{\mathrm{v}}\right)}{\rho\left(E_{\mathrm{v}}\right)}
$$

where $G^{\ddagger}\left(E_{\mathrm{v}}\right)$ is the sum of vibrational states of the TS, and $\rho\left(E_{\mathrm{v}}\right)$ is the density of vibrational states of the reactant. ${ }^{23}$ In an SCTST representation, ${ }^{32,48}$ all the vibrational modes of the TS and reactant are treated anharmonically. The common 
computation adapts the Wang-Landau algorithm, ${ }^{49-51}$ which is a random walk algorithm in energy space. The detailed discussions can be found in refs 25 and 52. For a system that involves 48 vibrational modes, the commonly chosen parameter values for iteration ${ }^{25,52}$ are not sufficient to achieve convergence. In addition, since some of the vibrational modes are only very weakly coupled with the reaction mode, it is unnecessary to perform a full-dimensional (FD) SCTST calculation.

In a 1D SCTST treatment, only one of the internal DoFs is treated anharmonically. The situation becomes simply RRKM with tunnelling calculated using 1D SCTST, which will be referred to as the RRKM-T for the remainder of this paper. Miller ${ }^{53}$ showed the quantum $G_{\mathrm{QM}}^{\ddagger}\left(E_{\mathrm{v}}\right)$ as a convolution of the classical density of state of the TS, $\rho^{\ddagger}\left(E_{\mathrm{v}}\right)$, and the 1D SCTST CRP, $P\left(E_{\mathrm{v}}\right)$ :

$$
G_{\mathrm{QM}}^{\ddagger}\left(E_{\mathrm{v}}\right)=\int_{-V_{\mathrm{f}}}^{E_{\mathrm{v}}-V_{\mathrm{f}}} \rho^{\ddagger}\left(E_{\mathrm{v}}-E_{1}\right) P\left(E_{1}\right) \mathrm{d} E_{1}
$$

This convolution can be easily computed using SteinRabinovitch extended Beyer-Swinehart (SRBS) algorithm ${ }^{54}$ with the $P\left(E_{\mathrm{v}}\right)$ as the starting array of computation. Note that this convolution is not limited to a $1 \mathrm{D}$ case. In a reduceddimensional (RD) case, one could treat $d$ active modes out of $F$ $(=3 N-6)$ internal vibrational modes anharmonically using SCTST and Wang-Landau algorithm. The resulting RD density of state can then be used as the starting array for an SRBS algorithm. The difficulty then becomes the choice of active modes, which is beyond the scope of the current study.

The experimental reaction rate constant is measured as a function of temperature. It can be directly compared to the canonical rate constant $k(T)$. At the high-pressure limit, it is given by $^{23,32,52}$

$$
k_{\text {SCTST }}(T)=\frac{1}{h} \frac{Q_{\text {rot }}^{\ddagger} Q_{\text {spec }}^{\ddagger} \int_{E_{\text {thresh }}}^{\infty} P\left(E_{\mathrm{v}}\right) \exp \left(-E_{\mathrm{v}} k_{\mathrm{B}}^{-1} T^{-1}\right) \mathrm{d} E_{\mathrm{v}}}{Q_{\mathrm{r}}}
$$

where $Q_{\text {rot }}^{\ddagger}$ is the rotational partition function of the TS, $Q_{\text {spec }}^{\ddagger}$ is the vibrational partition function of the spectator modes of the TS, $k_{\mathrm{B}}$ is the Boltzmann constant, and $Q_{\mathrm{r}}$ is the partition function of the reactant, which consists of the rotational and vibrational partition functions. To investigate the tunneling contribution in a reaction, we also compare our $k_{\mathrm{SCTST}}(T)$ to the transition-state theory result $k_{\mathrm{TST}}(T)$ given by

$$
k_{\mathrm{TST}}(T)=\frac{k_{\mathrm{B}} T}{h} \frac{Q^{\ddagger}}{Q_{\mathrm{r}}} \exp \left(-V_{\mathrm{f}} k_{\mathrm{B}}^{-1} T^{-1}\right)
$$

where $Q^{\ddagger}$ is the partition function of the TS that consists of both rotational and vibrational partition functions. The vibrational partition functions in Eqs 11 and 12 are calculated as a product of individual quantum harmonic oscillator partition functions for each vibrational modes. Some of the vibrational modes are also treated as hindered rotors. Detailed discussion of those modes and their partition functions can be found in Section 4.3. Note that, since a unimolecular decomposition reaction is studied in this work, some of the vibrational modes of the TS and the reactant may have very similar frequencies. The vibrational partition functions for those modes in Eqs 11 and 12 are likely to cancel out.

\section{PRACTICAL SPECIFICS}

3.1. Computational Details. All the computational calculations in this study were performed using the Gaussian $09^{55}$ quantum chemistry software package. The geometries of the stationary points were found using secondorder Møller-Plesset perturbation theory with an augmented correlation consistent polarized valence triple- $\zeta$ Dunning basis set $^{56-58}$ (MP2/aug-cc-pVTZ). In the remainder of the paper, we shall use aVTZ for convenience. We also make use of the jul-cc-pVTZ basis set ${ }^{59}$ (abbreviated "jVTZ" for the rest of the paper) in some calculations for comparisons.

The keyword "tight" was used as the optimization condition, to ensure a better convergence in numerical third and fourth order derivative calculation. Note that this tighter optimization requirement has very little effect on the actual barrier height calculation. The Hessian matrices at each stationary structure were calculated at the same level of theory as the geometry optimization. Single-point energy calculations of these stationary structures were performed at the coupled cluster level including single, double, and perturbative triple excitations $(\operatorname{CCSD}(\mathrm{T}))$ with either aVTZ or jVTZ basis set. In addition, the single-point energies were extrapolated to the complete basis set (CBS) limit from aVTZ and aVDZ (denoting "aug-ccpVDZ") basis sets via the method of Halkier et al. ${ }^{60}$

We showed, in the past, ${ }^{25}$ that numerical differentiation with Richardson extrapolation can provide accurate estimation of the third and fourth order derivatives of the PES with respect to the normal modes. The third and fourth order derivatives can be calculated numerically using either the single-point energies or the second derivatives with respect to the normal modes calculated using the Hessian matrices. ${ }^{25}$ In a 1D SCTST, it is computationally inefficient to calculate the Hessian matrices at displaced geometries along one single vibrational mode, the reaction mode. We, therefore, only perform a single-point energy calculation at MP2/aVTZ level of theory for each displaced geometry. The choice of step size is discussed in Section 4.4.

3.2. Experimental Details. General experimental setup is as follows (see Supporting Information for full details). A bespoke vapor generator unit was used to furnish a controllable, steady supply of GB vapor in a carrier gas $\left(\mathrm{N}_{2}\right)$. This could be either directly sampled (sorbent tube) or diverted to a working tube (WT) contained within a temperature-controlled tube furnace (TF), where it was mixed with a preheated dilution gas $\left(\mathrm{N}_{2}\right)$ providing control of residence time and temperature. Post-TF sampling (cold traps) allowed for determination of GB survival via gas chromatography (GC) analysis.

The vapor generator is contained within a temperaturecontrolled insulated metal box fitted with a temperature sensor and high-power heater. This was mounted to the inlet face of the $\mathrm{TF}$ and maintained at $50{ }^{\circ} \mathrm{C}(323.15 \mathrm{~K})$. The vapor source comprises of a $54 \mathrm{~mL}$ test tube fitted with a Dreschel head supplied with $100 \mathrm{~mL} / \mathrm{min} \mathrm{N}_{2}$ carrier gas (scrubbed, preheated). Use of a smaller sample vial to contain the GB within the vapor source enabled control of liquid surface area and therefore evaporation rate.

Initially, GB vapor was diverted through a waste path, to allow sufficient time for system equilibration, and then subsequently diverted through a sorbent tube or through the TF. A sorbent tube sample is taken directly before (presample) and after (postsample) diversion through the TF; this establishes baseline vapor concentration. Diversion to the WT 
a) (S)-GB
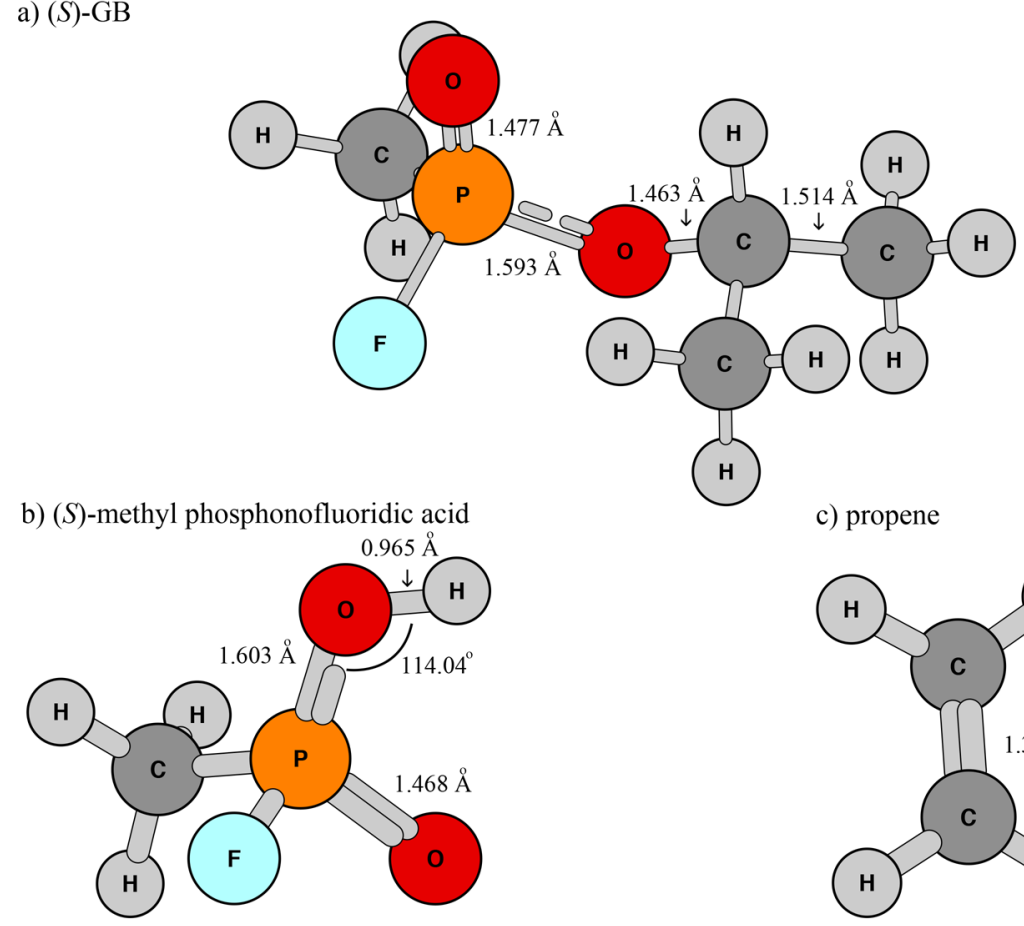

c) propene
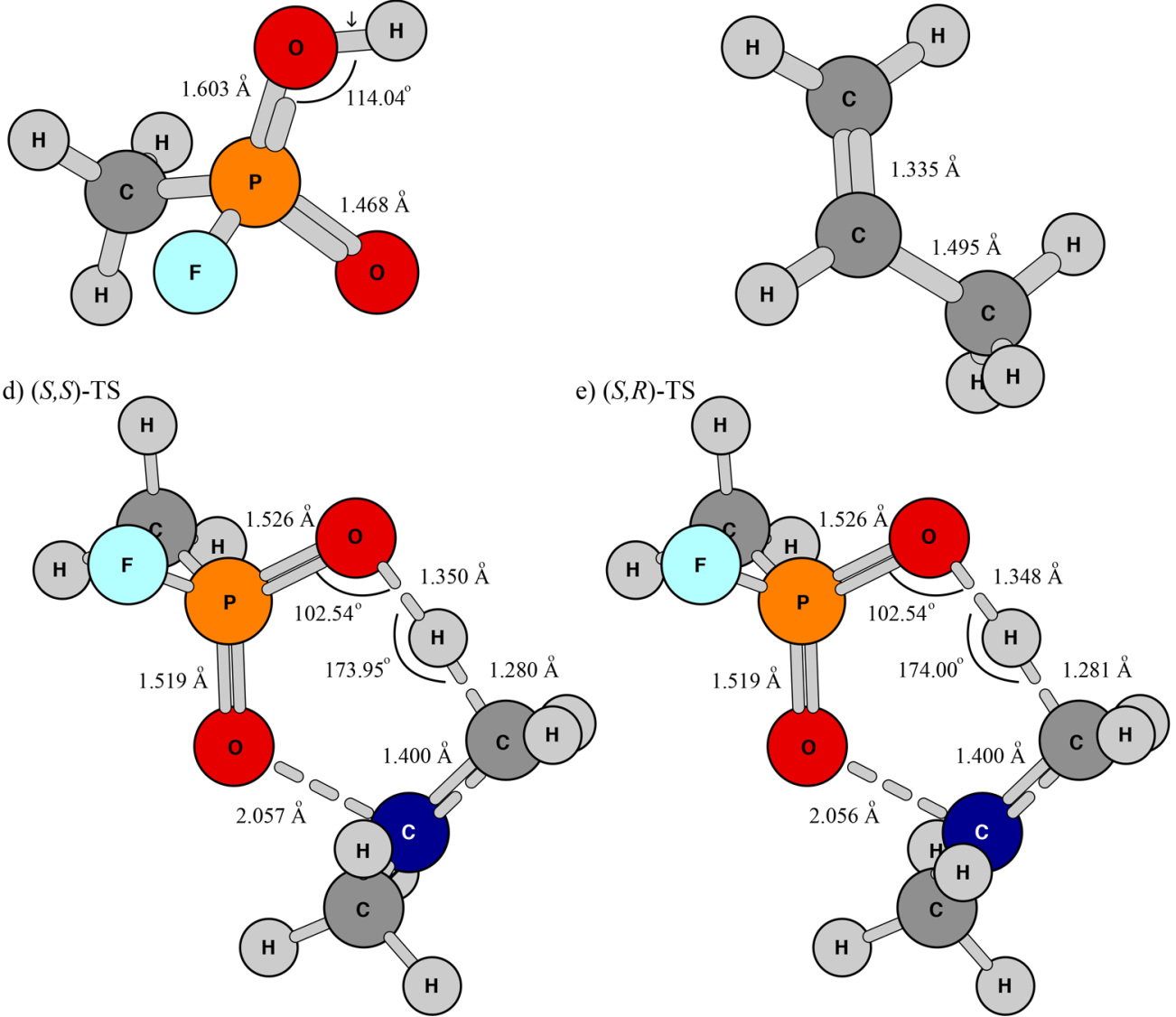

Figure 1. Optimized geometry of the stationary points of the reaction, (a) $(S)$-GB, (b) (S)-methyl phosphonofluoridic acid $\left((S)-\mathrm{CH}_{3} \mathrm{FPOOH}\right),(\mathrm{c})$ propene $\left(\mathrm{CH}_{2} \mathrm{CHCH}_{3}\right)$, (d) $(S, S)$-TS, and (e) $(S, R)$-TS.

and into the TF leads to mixing of the GB vapor with a flow of preheated dilution gas $\left(\mathrm{N}_{2}\right)$ of controlled temperature $(623.15$, $648.15,673.15,698.15,723.15,748.15$, and $773.15 \mathrm{~K})$. Variable-dilution gas flow rate allows for control of gas velocity and therefore vapor residence time $(0.5,0.25,0.125$, and 0.062 $\mathrm{s})$. A combination of experimental temperature profiling and thermal expansion calculations were used to confirm sufficient residence times.

Post-WT the GB vapor and carrier gas passed through fused silica coiled cold traps (CCTs) of $10 \mathrm{~mL}$ internal volume. The CCTs were submerged in liquid $\mathrm{N}_{2}$ during the experiment. Four consecutive solvent extractions (2-propanol, $1 \times 10 \mathrm{~mL}, 3$ $\times 5 \mathrm{~mL}$ ) were used, and the samples were analyzed (triplicate injection) by standard GC-FPD methods to furnish GB survivability data (fractional survivability = CCT recovery/ (pre-sample + post-sample/2)).

\section{RESULTS AND DISCUSSIONS}

4.1. Stationary Point Geometries. We show in Figure 1 the optimized geometries of the stationary species of the pericyclic reaction of GB. Some of the key bond lengths and bond angles are shown. Note that both GB and methyl phosphonofluoridic acid $\left(\mathrm{CH}_{3} \mathrm{FPOOH}\right)$ have chiral centers at the $\mathrm{P}$ atom. The structures shown in Figure $1 \mathrm{a}, \mathrm{b}$ are the $(S)$-GB and $(S)-\mathrm{CH}_{3} \mathrm{FPOOH}$, respectively. Figure 1c shows the other decomposition product, propene. The pericyclic reaction of the $(R)$-GB enantiomer has the same mechanism, and it yields only (R)- $\mathrm{CH}_{3} \mathrm{FPOOH}$. The TS of the pericyclic reaction consists of two chiral centers. The two diastereomers of the TS are shown 
in Figure 1d,e. The second chiral center is found at the $\mathrm{C}$ atom marked as dark blue on the figure. In GB, there are two $\mathrm{CH}_{3}$ groups attached to this $\mathrm{C}$ atom, and it is not chiral. However, at the TS, one of the $\mathrm{CH}_{3}$ group is directly involved in the reaction transferring one of its $\mathrm{H}$ atom to the $\mathrm{O}$ atom, while the other is not. The two $\mathrm{CH}_{3}$ groups are thus in different chemical environments and create the additional chirality at the $\mathrm{C}$ atom. If we take the plane that consists of the $\mathrm{P}-\mathrm{O}-\mathrm{C}$ triatoms as the reference plane, then the $(S, S)$-conformer (Figure 1d) of the TS corresponds to the $\mathrm{CH}_{3}$ groups attached to the $\mathrm{P}$ atom and $\mathrm{C}$ atom are on different sides of the plane, while the $(S, R)$ conformer (Figure 1e) has the two on the same side of the plane. Here the first " $S$ " and second " $S$ " or " $R$ " indicate the chirality at the $\mathrm{P}$ atom and $\mathrm{C}$ atom, respectively. Note that the chirality at the $\mathrm{C}$ atom does not affect the $\mathrm{P}$ atom side, so both of the TS structures in Figure 1d,e produce the same products: (S) $-\mathrm{CH}_{3} \mathrm{FPOOH}$ and $\mathrm{CH}_{2} \mathrm{CHCH}_{3}$.

It can be seen that, in both TS structures presented in Figure $1 \mathrm{~d}, \mathrm{e}$, there is a six-atom ring consisting of, in clockwise order, $\mathrm{H}, \mathrm{C}, \mathrm{C}, \mathrm{O}, \mathrm{P}, \mathrm{O}$ atoms. These six atoms are almost in a planar conformation, with only the $\mathrm{H}$ atom slightly out of plane. The reaction mode consists of the formation of three chemical bonds: $\mathrm{H}-\mathrm{O}$ single bond, $\mathrm{O}=\mathrm{P}$ double bond (the double bond that is formed in methyl phosphonofluoridic acid), and $\mathrm{C}=\mathrm{C}$ double bond, as well as the breaking of three chemical bonds: $\mathrm{P}=\mathrm{O}$ double bond (the double bond in $\mathrm{GB}$ ), $\mathrm{O}-\mathrm{C}$ single bond, and $\mathrm{C}-\mathrm{H}$ single bond. All of the six bond distances are stretched or squeezed accordingly when comparing the TS structures to the reactant. The two TS structures have almost the same values of the bond lengths and bond angles of the six-atom ring. We note that the $\mathrm{O}-\mathrm{C}$ single bond has a stretch of almost half of its equilibrium value, from $1.463 \AA$ in GB to $2.057 \AA$ in the $(S, S)$-TS and $2.056 \AA$ in the $(S, R)-T S$. The $\mathrm{H}$ atom and $\mathrm{CH}_{3}$ group attached to the darkblue-marked $\mathrm{C}$ atom exhibits structural profile more similar to the product $\left(\mathrm{CH}_{2} \mathrm{CHCH}_{3}\right)$ than to the reactant. The $\mathrm{C}-\mathrm{C}$ bond distance in this six-member ring $(1.400 \AA)$ is also closer to a $\mathrm{C}=\mathrm{C}$ double bond than a $\mathrm{C}-\mathrm{C}$ single bond. Our calculated bond lengths and angles at the $(S, R)$-TS agree well with the values reported in ref 22; however, the $(S, S)$-TS conformer was not identified in ref 22.

To understand the formation of the two TS conformers, we show the Newman projections of the $(S)$-GB in Figure 2a and

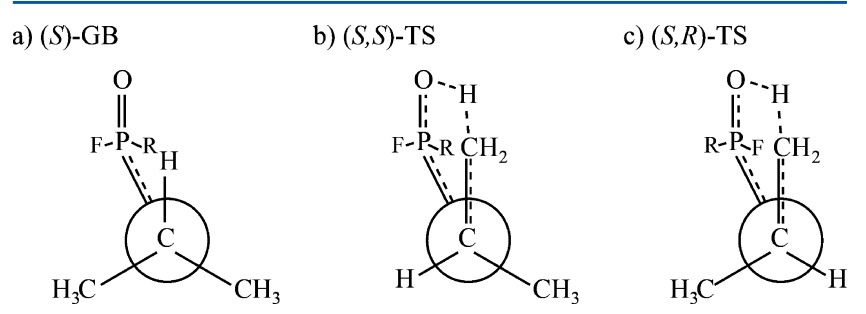

Figure 2. Schematic Newman projections of the TS, (a) (S)-GB, (b) $(S, S)$-TS, and (c) $(S, R)$-TS. In all three panels, "R" indicates the $\mathrm{CH}_{3}$ group attached to the $\mathrm{P}$ atom.

TSs in Figure $2 b, c$ along the $\mathrm{C}-\mathrm{O}$ bond. The direction of the internal rotation across the $\mathrm{C}-\mathrm{O}$ bond in $(S)$-GB produces the two conformers, with anticlockwise rotation leading to the $(S, S)$-TS and clockwise rotation leading to the $(S, R)$-TS. In our intrinsic reaction coordinate calculation, we found that the stretching of the $\mathrm{C}-\mathrm{O}$ bond accompanies this internal rotation from $(S)$-GB to either of the two TSs. Similar result was found in ref 22 for the reaction path through the $(S, R)-T S$. We make the assumption that once the molecule reaches either of the two TSs it will proceed to form the products, so that this internal rotation does not continue at the TS. In other words, from the equilibrium structure of the reactant, only anticlockwise rotation across the $\mathrm{C}-\mathrm{O}$ bond yields the $(S, S)$ TS, and only clockwise rotation yields the $(S, R)-T S$. The overall reaction rate constant is therefore only half of the sum of the two reaction branches.

4.2. Reaction Energetics. We took the reaction path through the $(S, S)$-TS as a testing case for the reaction barrier and enthalpy at different level of theories. The results are shown in Table 1. It is very interesting to see that the values of

Table 1. Table of the Reaction Energetics for the $(S, S)$-TS at Various Levels of Theory ${ }^{a}$

\begin{tabular}{clcc} 
geom/freq level & \multicolumn{1}{c}{ energy level } & $\Delta V_{\mathrm{a}}^{\ddagger}$ & $\Delta H_{\mathrm{r}}$ \\
$\mathrm{MP} 2 / \mathrm{jVTZ}$ & $\mathrm{MP} 2 / \mathrm{jVTZ}$ & 167.1 & 80.96 \\
& $\mathrm{CCSD}(\mathrm{T}) / \mathrm{VTZ}$ & 169.7 & 90.91 \\
& $\mathrm{CCSD}(\mathrm{T}) / \mathrm{jVTZ}$ & 167.2 & 81.69 \\
$\mathrm{MP} 2 / \mathrm{aVTZ}$ & $\mathrm{MP} 2 / \mathrm{aVTZ}$ & 166.1 & 86.84 \\
& $\mathrm{CCSD}(\mathrm{T}) / \mathrm{VTZ}$ & 169.9 & 78.77 \\
& $\mathrm{CCSD}(\mathrm{T}) / \mathrm{jVTZ}$ & 167.3 & 81.66 \\
& $\mathrm{CCSD}(\mathrm{T}) / \mathrm{aVTZ}$ & 166.1 & 82.40 \\
& $\mathrm{CCSD}(\mathrm{T}) / \mathrm{CBS}$ & 165.5 & 80.33
\end{tabular}

${ }^{a}$ The VTZ denotes the cc-pVTZ basis set. All the values are in kilojoules per mole.

calculated adiabatic barrier $\Delta V_{\mathrm{a}}^{\dagger}$ of the reaction are very close for all the levels of theory that we tested. A general trend is that it is converging toward higher level of theory with larger basis set. In the current study, the highest level of theory used is $\mathrm{MP} 2 / \mathrm{aVTZ}$ for the geometry optimization and frequency calculation and $\operatorname{CCSD}(\mathrm{T}) / \mathrm{CBS}$ extrapolated using aVTZ and aVDZ basis sets for single-point energy corrections. This calculation estimates the adiabatic barrier of the reaction is $165.5 \mathrm{~kJ} / \mathrm{mol}$. Interestingly, the MP2/aVTZ level of theory also predicts the same barrier height produced at $\operatorname{CCSD}(\mathrm{T}) / \mathrm{aVTZ}$ level. However, it underestimates the reverse barrier height, and hence overestimates the reaction enthalpy $\Delta H_{\mathrm{r}}$, the value of which is also converging toward the highest level of theory. It is worth noting that the reaction has a large difference in the forward and reverse barrier heights; the deep tunneling correction should be included in the 1D SCTST calculation for this reaction to achieve better estimation of this largely unsymmetrical barrier. Since the deep tunneling correction used in the 1D SCTST calculation requires both the forward and reverse barrier of the reaction, we used the values from $\operatorname{CCSD}(\mathrm{T}) / \mathrm{CBS}$ level of theory, $165.5 \mathrm{~kJ} / \mathrm{mol}$ for $\Delta V_{\mathrm{a}}^{\ddagger}$ and $80.33 \mathrm{~kJ} / \mathrm{mol}$ for $\Delta H_{\mathrm{r}}$, in the calculation of rate constants. The $\operatorname{CCSD}(\mathrm{T}) / \mathrm{VTZ}$ level of theory produces barrier heights and reaction enthalpies that have largest deviation from the results of the highest level of theory, because the basis set does not include diffuse functions, which are very important for calculations of modules that has third-row elements. ${ }^{61}$ Another interesting finding is that the jVTZ results are very close to the highest level of theory, even with the geometry and frequencies calculated at MP2/jVTZ level.

We also performed calculations at the MP2/aVTZ// $\operatorname{CCSD}(\mathrm{T}) / \mathrm{CBS}$ level for the reaction through the $(S, R)-\mathrm{TS}$ and found $\Delta V_{\mathrm{a}}^{\ddagger}$ of $166.6 \mathrm{~kJ} / \mathrm{mol}$, which is $1 \mathrm{~kJ} / \mathrm{mol}(0.6 \%)$ higher than the barrier of the $(S, S)$-TS. It is in a very good 
Table 2. Table of Vibrational Frequencies $\left(\right.$ in $\mathrm{cm}^{-1}$ ) of the Stationary Structures at MP2/aVTZ Level of Theory ${ }^{a}$

\begin{tabular}{|c|c|c|c|c|c|c|c|}
\hline \multicolumn{4}{|c|}{ GB } & \multicolumn{4}{|c|}{$(S, S)-\mathrm{TS}$} \\
\hline 3206.52 & 3202.28 & 3176.23 & 3172.74 & $1162.02(\mathrm{i})$ & 3248.19 & 3228.62 & 3206.63 \\
\hline 3169.76 & 3162.98 & 3108.01 & 3095.21 & 3197.10 & 3194.80 & 3148.43 & 3140.51 \\
\hline 3075.27 & 3071.21 & 1526.04 & 1513.71 & 3088.37 & 3056.78 & 1585.37 & 1511.79 \\
\hline 1501.56 & 1499.53 & 1478.09 & 1475.55 & 1478.04 & 1477.27 & 1475.74 & 1457.64 \\
\hline 1425.19 & 1417.42 & 1390.00 & 1381.36 & 1403.15 & 1389.90 & 1340.83 & 1338.92 \\
\hline 1348.33 & 1298.28 & 1211.34 & 1186.25 & 1314.01 & 1258.93 & 1209.63 & 1138.53 \\
\hline 1139.22 & 1035.64 & 960.59 & 945.28 & 1066.89 & 1006.16 & 956.36 & 925.52 \\
\hline 941.84 & 923.60 & 904.65 & 845.56 & 920.72 & 907.91 & 895.21 & 845.16 \\
\hline 788.82 & 736.83 & 508.82 & 475.44 & 769.87 & 666.65 & 568.95 & 498.92 \\
\hline 409.42 & 405.51 & 375.58 & 309.70 & 471.61 & 449.05 & 409.69 & 355.49 \\
\hline 271.61 & 263.12 & 238.17 & 229.10 & 340.25 & 294.47 & 260.58 & 236.90 \\
\hline 183.15 & 142.40 & 67.40 & 37.00 & 197.14 & 193.35 & 58.17 & 44.43 \\
\hline \multicolumn{4}{|c|}{$\mathrm{CH}_{3} \mathrm{FPOOH}$} & \multicolumn{4}{|c|}{$(S, R)-\mathrm{TS}$} \\
\hline 3841.00 & 3199.67 & 3195.96 & 3091.26 & $1187.80(\mathrm{i})$ & 3246.92 & 3228.05 & 3205.26 \\
\hline 1481.91 & 1475.46 & 1365.38 & 1340.19 & 3198.98 & 3196.73 & 3146.85 & 3140.51 \\
\hline 1002.73 & 956.78 & 907.03 & 887.69 & 3089.13 & 3057.05 & 1584.41 & 1511.88 \\
\hline 846.55 & 751.93 & 459.64 & 404.37 & 1479.00 & 1476.97 & 1475.14 & 1454.45 \\
\hline 395.70 & 298.75 & 270.15 & 202.89 & 1405.57 & 1393.09 & 1346.70 & 1338.10 \\
\hline 189.77 & & & & 1290.29 & 1262.12 & 1207.83 & 1131.88 \\
\hline \multicolumn{4}{|c|}{$\mathrm{CH}_{2} \mathrm{CHCH}_{3}$} & 1060.52 & 1005.11 & 956.44 & 924.20 \\
\hline 3270.26 & 3183.21 & 3169.95 & 3157.02 & 918.79 & 907.75 & 896.82 & 841.17 \\
\hline 3136.29 & 3062.35 & 1699.47 & 1513.07 & 764.38 & 664.28 & 569.07 & 498.42 \\
\hline 1499.56 & 1457.67 & 1413.00 & 1324.33 & 457.31 & 445.86 & 412.71 & 354.61 \\
\hline 1196.88 & 1073.71 & 1027.58 & 945.67 & 342.85 & 269.80 & 256.55 & 246.33 \\
\hline 940.45 & 933.90 & 588.31 & 420.43 & 205.01 & 189.76 & 56.11 & 41.51 \\
\hline 207.82 & & & & & & & \\
\hline
\end{tabular}

${ }^{a}$ The imaginary frequency corresponding to the reaction modes in the TSs are marked with "(i)".

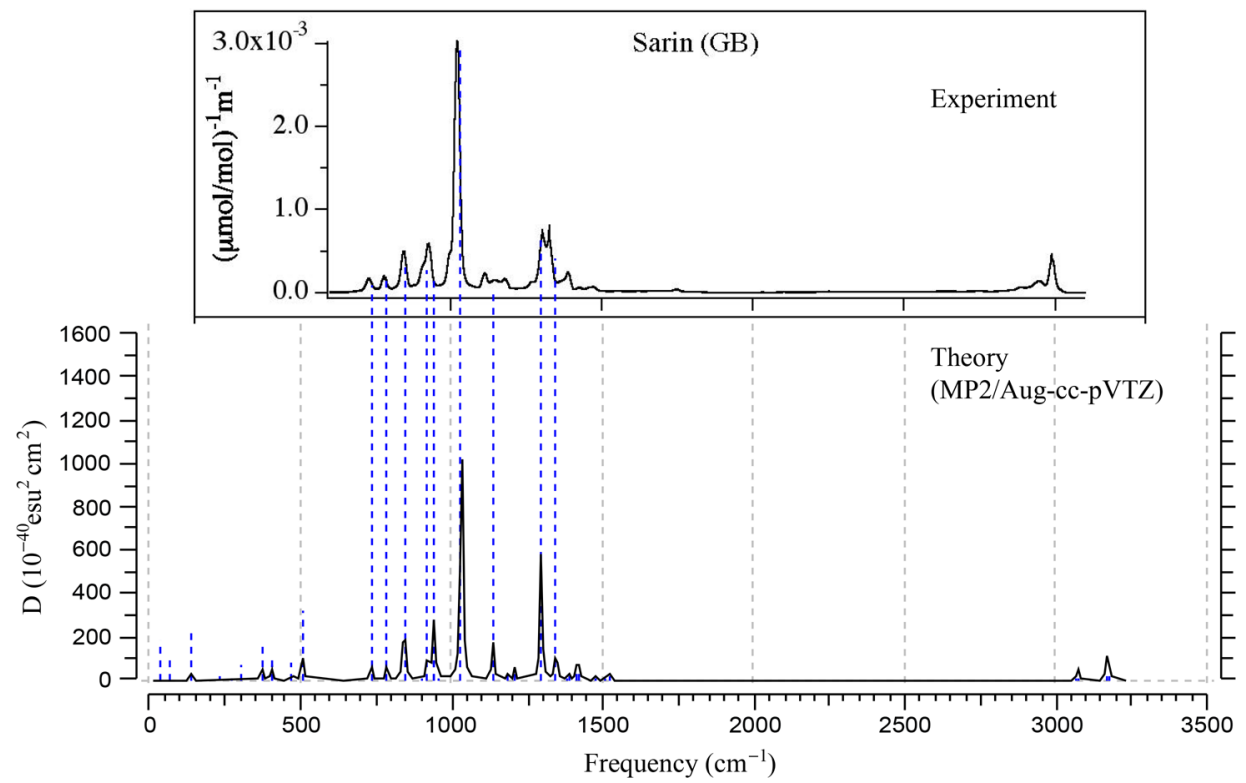

Figure 3. Comparison of the IR spectra of GB between calculation of MP2/aVTZ level of theory and experimental data reported by Sharpe et al. ${ }^{15}$

agreement with the previous theoretical result of $163.6 \mathrm{~kJ} / \mathrm{mol}$ at CBS-QB3 level of theory. ${ }^{22}$ Note that the value of the reaction enthalpy remains the same, since the reactant and product are the same, and hence the reverse barrier for the $(S, R)$-TS is also $1 \mathrm{~kJ} / \mathrm{mol}$ higher than that of the $(S, S)$-TS.

4.3. Vibrational Analyses. We show the vibrational frequencies of all the stationary structures in Table 2. The comparison between our results and experimental data ${ }^{15}$ for GB is shown in Figure 3. It can be seen the two agree well in the range between 750 and $1500 \mathrm{~cm}^{-1}$. In particular, Sharpe and co-workers ${ }^{15}$ reported the maximum absorption coefficient corresponds to the $\mathrm{P}-\mathrm{O}-\mathrm{C}$ stretch between 1000 and 1050 $\mathrm{cm}^{-1}$; our calculated value for this vibrational mode is 1035.64 $\mathrm{cm}^{-1}$. The $\mathrm{P}=\mathrm{O}$ stretch associated with electronegative $\mathrm{F}$ atom 
is shown as the characteristic doublet near $1317 \mathrm{~cm}^{-1} .15$ Our calculation has two peaks at 1298.28 and $1348.33 \mathrm{~cm}^{-1}$, and both of these vibrational modes have strong $\mathrm{P}=\mathrm{O}$ stretching behavior. Our calculation has an overestimation of $\sim 100 \mathrm{~cm}^{-1}$ for the frequencies of the $\mathrm{C}-\mathrm{H}$ stretching modes. The reaction modes of the $(S, S)$-TS and the $(S, R)$-TS have vibrational frequencies of 1162.02 and $1187.80 \mathrm{~cm}^{-1}$, respectively, which are $\sim 500 \mathrm{~cm}^{-1}$ smaller than in a typical bimolecular $\mathrm{H}$ abstraction $^{25,62,63}$ or H-exchange ${ }^{64}$ reactions in the gas phase.

Note that there are several very low-frequency vibrational modes for the reactant and the TSs. We analyzed these through the eigenvectors of those modes. They correspond to the internal rotations of various fragments of the molecule, in particular, the $\mathrm{CH}_{3}$ groups. A full-dimensional dynamic model for the current system, although it provides the most accurate treatment to these hindered rotor vibrational modes, is computationally too expensive to perform. In addition these hindered rotor vibrations only have limited contribution to the reaction mechanism in terms of coupling with the reaction mode. We therefore employ approximate treatments developed by Truhlar and co-workers. ${ }^{26-29}$ Detailed discussions of the multistructural method based on including all structures/ conformers generated by internal rotation, or the so-called MSAS method, can be found in ref 29. In this particular study, we treat the internal rotations of the $\mathrm{CH}_{3}$ groups in GB and the TSs using a simplified version of MS-AS, where only a single conformer is used for states. The correction to the partition functions of a system consisting of $t$ number of hindered rotors can be written as follows: ${ }^{29}$

$$
c_{\mathrm{HR}}=Z \prod_{\tau=1}^{t} f_{\tau}
$$

with

$$
f_{\tau}=\frac{\bar{\omega}_{\tau} \sqrt{2 \pi \beta k_{\tau}}}{M_{\tau}} \exp \left(-\frac{\beta I_{\tau}}{M_{\tau}^{2}}\right) I_{0}\left(\frac{\beta I_{\tau}}{M_{\tau}^{2}}\right)
$$

and

$$
Z=g+(1-g) \frac{\prod_{m=1}^{F-t} \overline{\bar{\omega}}_{m}^{-1} \prod_{\tau=1}^{t} \bar{\omega}_{\tau}^{-1}}{\prod_{m=1}^{F} \omega_{m}^{-1}}\left(\frac{|\operatorname{det} \mathbf{D}|}{\prod_{\tau=1}^{t} I_{\tau}}\right)^{1 / 2}
$$

where

$$
g=\left[\prod_{\tau=1}^{t} \tanh \left(\frac{\sqrt{2 \pi k_{\tau} \beta}}{M_{\tau}}\right)\right]^{1 / t}
$$

Here $\bar{\omega}_{\tau}, k_{\tau}, M_{\tau}$, and $I_{\tau}$ are the frequency, force constant, number of minima, and moment of inertia for the $\tau$ th hindered rotor, respectively. $I_{0}$ is a modified Bessel function, and $\beta$ is $1 /$ $k_{\mathrm{B}} T . \omega_{m}$ is the harmonic frequency of the $m$ th vibration as reported in Table 2, and $\overline{\bar{\omega}}_{m}$ is the frequency of the $m$ th nonhindered-rotor vibrational modes. ${ }^{29} \mathbf{D}$ is the kinetic energy matrix for internal rotation. ${ }^{65-67}$

4.4. Anharmonicity Calculations for the Reaction Mode. In our previous study, ${ }^{25}$ we employed two different types of step size choices in numerically determining the third and fourth order derivatives of the PES with respect to normal modes. In the 1D SCTST case, ${ }^{25}$ the same displacement value of $\Delta Q=0.02 \mathrm{D}_{\mathrm{a}}{ }^{1 / 2} a_{0}$ was used for the two reactions $\mathrm{H}+\mathrm{CH}_{4}$ and $\mathrm{H}+\mathrm{C}_{2} \mathrm{H}_{6}$. This value can be converted into a displacement $\Delta q$ in reduced normal coordinates as follows: ${ }^{68-70}$

$$
\Delta Q=\frac{\hbar^{1 / 2}}{\omega^{1 / 2}} \delta q
$$

Thus, the displacement was $\sim 0.075$ in reduced normal coordinates for those two reactions. ${ }^{25}$ We applied the same approach in the current study, and the displacement in reduced normal coordinates is 0.062 for $(S, S-T S)$ and 0.061 for $(S, R$ TS). The resulting third and fourth order derivatives with

\begin{tabular}{|c|c|c|c|c|c|c|}
\hline \multirow{4}{*}{$\Delta Q$} & \multicolumn{6}{|c|}{$(S, S)-\mathrm{TS}$} \\
\hline & \multicolumn{3}{|c|}{ Third $\times 10^{6}$} & \multicolumn{3}{|c|}{ Fourth $\times 10^{7}$} \\
\hline & \multicolumn{6}{|c|}{ Extrapolation Order } \\
\hline & 0 & 1 & 2 & 0 & 1 & 2 \\
\hline 0.02 & 1.981 & 1.981 & 1.981 & 3.324 & 3.327 & 3.327 \\
\hline 0.04 & 1.981 & 1.981 & - & 3.316 & 3.321 & - \\
\hline 0.08 & 1.979 & - & - & 3.300 & - & - \\
\hline \multirow{4}{*}{$\Delta Q$} & \multicolumn{6}{|c|}{$(S, R)-\mathrm{TS}$} \\
\hline & \multicolumn{3}{|c|}{ Third $\times 10^{6}$} & \multicolumn{3}{|c|}{ Fourth $\times 10^{7}$} \\
\hline & \multicolumn{6}{|c|}{ Extrapolation Order } \\
\hline & 0 & 1 & 2 & 0 & 1 & 2 \\
\hline 0.02 & -2.000 & -2.000 & -2.000 & 3.405 & 3.407 & 3.407 \\
\hline 0.04 & -1.999 & -2.000 & - & 3.398 & 3.404 & - \\
\hline 0.08 & -1.998 & - & - & 3.381 & - & - \\
\hline
\end{tabular}
Richardson extrapolation up to the order of 2 are shown in Table 3. Note that, to calculate the zeroth-order third and

Table 3. Table of Third and Fourth Order Derivatives of the PES $^{a}$

${ }^{a}$ With respect to reaction mode of both TSs in atomic unit. The results of Richardson extrapolation up to the order of 2 are shown.

fourth order derivatives using step size $\Delta Q=0.08 \mathrm{D}_{\mathrm{a}}{ }^{1 / 2} a_{0}$, the single-point energies at $\Delta Q= \pm 0.16 \mathrm{D}_{\mathrm{a}}{ }^{1 / 2} a_{0}$ are required. We, therefore, calculated the single-point energies of in total eight displaced geometries along the reaction mode for each TS to generate Table 3.

From Table 3, it can be seen that the step size increase has less effect on the third order derivative than the fourth. All of the derivatives show convergence at their values as the extrapolation order increases. Comparing to the second-order values, the third order derivative converges faster than the fourth for both TSs. In the previous study, ${ }^{25}$ we found that Richardson extrapolation has very small effect on the resulting $x_{\mathrm{FF}}$ and $G_{0}$ in 1D SCTST. It shows here that the zeroth-order $\Delta Q=0.02 \mathrm{D}_{\mathrm{a}}{ }^{1 / 2} a_{0}$ third and fourth order derivatives are indeed very close to the converged second-order results. Although in the current study using zeroth-order results is likely to almost have no impact in the resulting rate constants, we used the slightly more accurate second-order extrapolated derivatives in the calculations of $x_{\mathrm{FF}}, G_{0}$, and 1D SCTST rate constants.

4.5. Reaction Rates. Plots of the calculated microcanonical $(k(E))$ and macrocanonical $(k(T))$ rate constants are shown in Figure $4 \mathrm{a}, \mathrm{b}$, respectively. We first compare $k_{\mathrm{RRKM}-\mathrm{T}}(E)$ (solid black curve) to the normal $\operatorname{RRKM}^{23}$ rate constant $k_{\mathrm{RRKM}}(E)$ (dashed red curve) in Figure $4 \mathrm{a}$, where $k_{\mathrm{RRKM}}(E)$ is calculated using Eq 9 with an initial density array. ${ }^{54}$ Note that the only difference in the computation of $k_{\mathrm{RRKM}-\mathrm{T}}(E)$ and $k_{\mathrm{RRKM}}(E)$ is the initial density array, where the RRKM-T includes the tunnelling contribution calculated using the 1D SCTST 

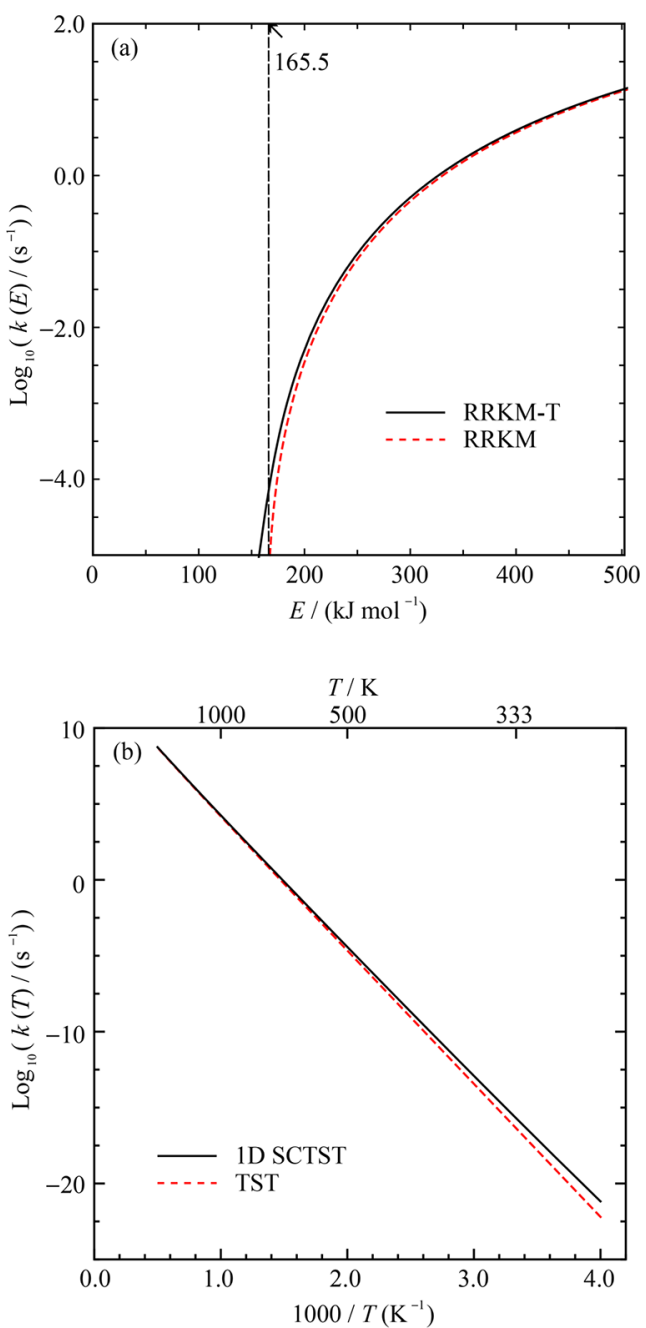

Figure 4. Plots of theoretical reaction rate constants. (a) Microcanonical rate constants $k(E)$, with RRKM-T as solid black curve and RRKM as dashed red curve. (b) Macrocanonical at high pressure limit $k(T)$, with 1D SCTST as solid black curve and TST as dashed red curve.

method. We therefore use $k(E)$ to investigate the tunneling contribution to the reaction rate and not to compare with our experimental results. In addition, the hindered rotor modes were treated only as harmonic oscillators in the calculation of $k(E)$, although more accurate methods that include them are available. ${ }^{54}$ We can see that the two curves converge at high energy as expected. The tunneling effect calculated using 1D SCTST only has small contribution to the reaction rate for energy lower than typically $300 \mathrm{~kJ} / \mathrm{mol}$. At $300 \mathrm{~kJ} / \mathrm{mol}$, normal RRKM estimates a rate constant of $6.242 \times 10^{3} \mathrm{~s}^{-1}$, while with tunneling the rate constant is $8.820 \times 10^{3} \mathrm{~s}^{-1}$. At a lower energy, for instance, $200 \mathrm{~kJ} / \mathrm{mol}$, the RRKM-T rate constant $\left(25.84 \mathrm{~s}^{-1}\right)$ is approximately twice as much as without tunneling $\left(12.11 \mathrm{~s}^{-1}\right)$. At energy below the adiabatic barrier, $165.5 \mathrm{~kJ} / \mathrm{mol}$, a small rate constant is suggested by the RRKM$\mathrm{T}$, which clearly indicates that quantum tunneling contributes to the reaction. Note that the smaller barrier of the two TSs is used here; it is marked on Figure $4 a$ as the vertical dashed line.

In Figure $4 b$, we compare the macrocanonical reaction rate constants estimated for the high pressure limit using our 1D SCTST (solid black curve) and the TST (dashed red curve). The two curves converges at high $T$, typically above $1000 \mathrm{~K}$.
The 1D SCTST estimates a slightly faster reaction rate than the TST on this logarithm plot. The difference between the two curves is clearer at $T$ below $300 \mathrm{~K}$. At $600 \mathrm{~K} k_{\text {SCTST }}$ is only 1.5 times of $k_{\mathrm{TST}}$, while at $300 \mathrm{~K}$ it is 5 times faster than $k_{\mathrm{TST}}$. Overall, we can see a tunneling contribution to the reaction mechanism, but its impact on the rate constant seems to be small.

In the experiment, the GB percentage survival rate is measured at different times and at temperature ranged from 598.15 to $798.15 \mathrm{~K}$. It is easily compared to the our calculated rate constants using the following equation:

$$
\text { GB\%survival }=\frac{[\mathrm{GB}]}{[\mathrm{GB}]_{0}} \times 100=\exp [-k(T) t] \times 100
$$

where $k(T)$ is the rate constant, and $t$ is time. Note that $k(T)$ in this equation can be either $k_{\text {SCTST }}(T)$ or $k_{\text {TST }}(T)$. This equation can also be used to provide an estimation of the experimental reaction rate constant. In Figure 5 the comparison of GB percentage survival between the 1D SCTST (colored curves) and experiments (dots) is shown. There is good agreement in all cases. The best agreement is shown for the $0.5 \mathrm{~s}$ case (purple
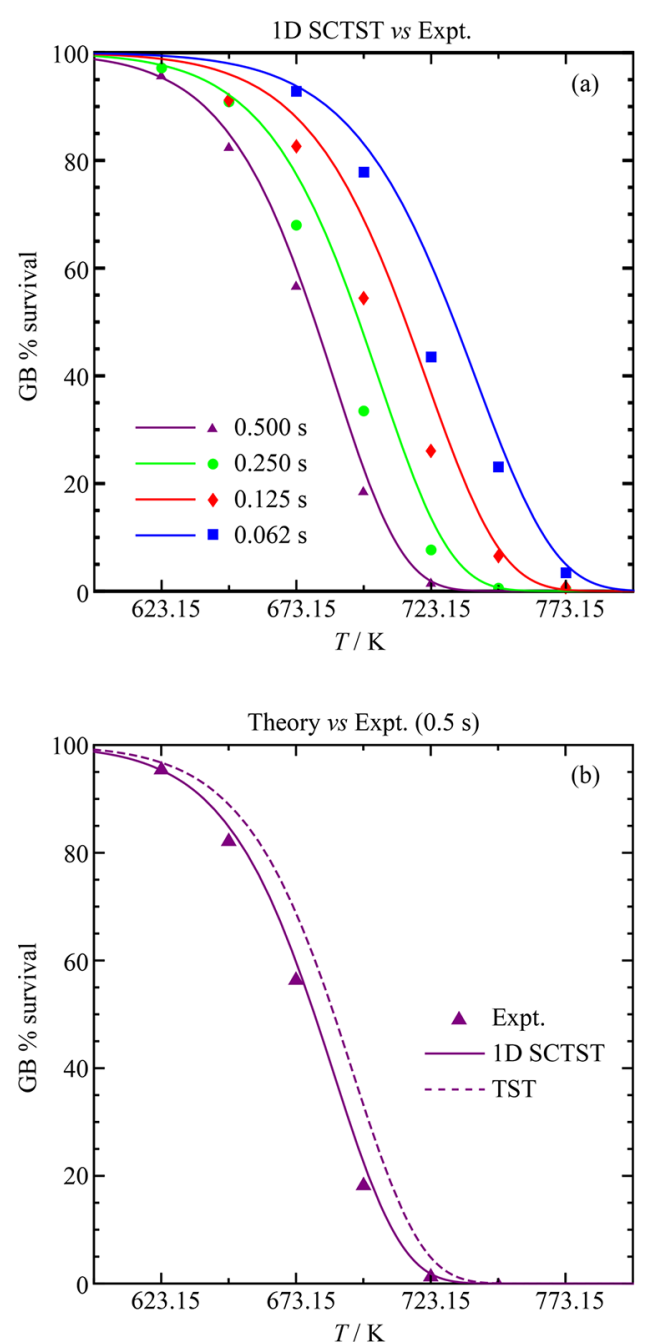

Figure 5. Plots of GB percentage survival at various time vs temperature. (a) Comparison between 1D SCTST (curves) and experimental data (dots), and (b) comparison between 1D SCTST (solid curve), TST (dashed curve), and experimental data (dots). 
curves and dots). Note that the experimental work was performed at temperatures that are normally considered as relatively high and that the quantum tunneling effect is normally considered to have little impact at these temperatures. We investigate this point in Figure $5 b$ by comparing the GB \% survival after $5 \mathrm{~s}$ calculated using 1D SCTST (solid purple curve) and TST (dashed purple curve) to experiment (dots). As seen before in Figure 5a, on the one hand, the 1D SCTST curve has a very good agreement with the experiment. The TST results, on the other hand, show clear overestimation to the GB \%survival. For instance, at $673.15 \mathrm{~K}$, TST suggests $\sim 10 \%$ additional survival percentage comparing to the 1D SCTST estimation and the experimental data. We also compared the GB \%survival calculated using TST to the experimental data at other times and found overestimation in all cases. This overestimation of \%survival indicates underestimation of the rate constants. It suggests that even at this high temperature conditions, the quantum tunneling effect still has a very important role to the reaction.

The experimental estimation of the rate constant can be computed by reverse engineering of Eq 18 . We show the results in Figure 6. The difference between 1D SCTST and

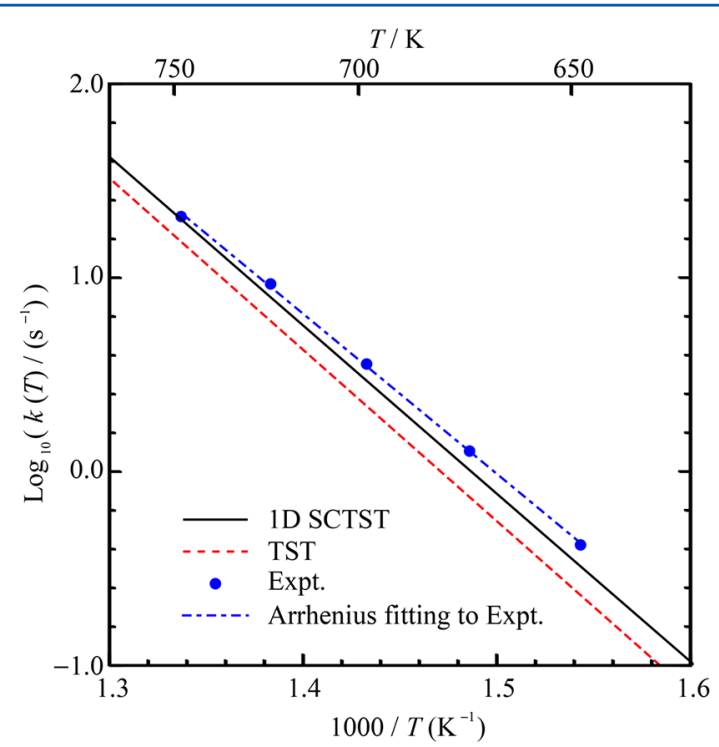

Figure 6. Macrocanonical rate constant at high temperature from 625 to $750 \mathrm{~K}$, with 1D SCTST results as solid black curve, TST results as dashed red curve, experimental data as blue dots, and the Arrhenius fitting to the experimental data as dash-dotted blue curve.

experiments is within $10 \%$ for temperature above $700 \mathrm{~K}$ with the experiment suggesting a slightly faster reaction. The $1 \mathrm{D}$ SCTST underestimates the rate constants at $648.15 \mathrm{~K}$ by $\sim 25 \%$ comparing to the experimental data, but it is 1.5 times faster than the TST rate constant. This result indicates once again even at relatively high temperature the quantum tunneling effect is playing an important role in this reaction. In addition, we also fitted the experimental rate constants using a simple Arrhenius equation:

$$
k_{\text {expt }}(T)=A \times \exp \left(-E_{\mathrm{a}} k_{\mathrm{B}}^{-1} T^{-1}\right)
$$

where $A$ is the pre-exponential factor, and $E_{\mathrm{a}}$ is the reaction barrier. The resulting reaction barrier is $\sim 158 \mathrm{~kJ} / \mathrm{mol}$. Its agreement to our theoretical results of the adiabatic reaction barrier is within $6 \%$.

\section{CONCLUSIONS}

An experimental and theoretical investigation of the thermal decomposition of GB for temperatures ranging from 623.15 to $773.15 \mathrm{~K}$ ( 350 to $500{ }^{\circ} \mathrm{C}$ ) has been performed. In particular, the pericyclic decomposition mechanism was studied. We performed geometry optimizations and frequency calculations at the MP2/aug-cc-pVTZ level of theory, and performed singlepoint energy calculation at $\operatorname{CCSD}(\mathrm{T}) / \mathrm{CBS}$ level of theory extrapolated using the aVTZ and aVDZ basis sets for each stationary structure. Our calculated adiabatic reaction barrier is $165.5 \mathrm{~kJ} / \mathrm{mol}$, which is very close to our experimental estimation of $\sim 158 \mathrm{~kJ} / \mathrm{mol}$.

The calculation identified a transition state with a sixmembered ring structure, and a reaction path involves a $\mathrm{H}$ atom transfer between two fragments of the molecule. We therefore used the 1D SCTST in the reaction rate constant calculation to include the possible quantum tunneling effect due to the $\mathrm{H}$-atom transfer. Adaptive differentiation to the order of two was employed to ensure the convergence of the numerical differentiation results in the estimation of the third and fourth order derivatives of the potential energy surface with respect to the reaction mode, which were in turn used to calculate the anharmonic constant of the reaction mode. This method requires in total only eight additional single energy calculations at displacement geometries at MP2/aug-cc-pVTZ level of theory comparing to a TST calculation. The resulting 1D SCTST rate constant and the dependency of GB \%survival on temperature and time showed very good agreement to our experimental measured results, while the TST underestimated the reaction rate constants. This suggested that quantum tunneling makes an important contribution to this reaction at relatively high temperature between 623.15 and $773.15 \mathrm{~K}$.

Our results showed that accurate theoretical methods can make a useful contribution to understanding the properties of nerve agents. Similar works can be performed on other nerve agents and highly toxic compounds that are difficult to study in the laboratory. An improved understanding of the thermal breakdown pathways of alkylphosphonofluoridates may also be valuable in relation to investigations of alleged use of nerve agents. The alkylphosphonofluoridic acids formed from alkene elimination do not occur naturally in the environment ${ }^{71}$ and may therefore serve as potential indicators of nerve agent use. Theoretical and experimental studies of the kind reported herein therefore also support the work of the Organisation for the Prohibition of Chemical Weapons (OPCW), which conducts such investigations.

\section{ASSOCIATED CONTENT}

\section{S Supporting Information}

The Supporting Information is available free of charge on the ACS Publications website at DOI: 10.1021/acs.jpca.7b04282.

Detailed experimental setup and measured results (PDF)

\section{AUTHOR INFORMATION}

\section{Corresponding Author}

*E-mail: xiao.shan@chem.ox.ac.uk

ORCID

Xiao Shan: 0000-0003-1603-0338

\section{Notes}

The authors declare no competing financial interest. 


\section{ACKNOWLEDGMENTS}

X.S. acknowledges the use of the Univ. of Oxford Advanced Research Computing (ARC) facility in performing the theoretical studies in this work. X.S. and D.C.C. are thankful for the financial support of the Leverhulme Trust (Project Grant No. RPG-2013-321). X.S. and D.C.C. acknowledge support from DSTL CT\&S R-Cloud Tender R100010-4370. The authors are grateful to the Analytical Chemistry Team and D. Francis of the CBR Division at DSTL for GC sample analysis. They also express thanks to P. Watts and S. Saunders (both CBR Division, DSTL), for laboratory support, and to Dr. N. Robinson and Dr. C. Timperley (CBR Division, DSTL), for scientific advice and guidance. Content includes material subject to Crown copyright (2017), DSTL. This material is licensed under the terms of the Open Government Licence except where otherwise stated. To view this licence, visit http://www.nationalarchives.gov.uk/doc/open-governmentlicence/version $/ 3$ or write to the Information Policy Team, The National Archives, Kew, London, TW9 4DU, or email psi@nationalarchives.gsi.gov.uk.

\section{REFERENCES}

(1) Kim, K.; Tsay, O. G.; Atwood, D. A.; Churchill, D. G. Destruction and Detection of Chemical Warfare Agents. Chem. Rev. 2011, 111, 5345-5403.

(2) Black, R. M.; Harrison, J. M. In The Chemistry of Organophosphorus Chemical Warfare Agents; Hartley, F. R., Ed.; The Chemistry of Organophosphorus Compounds; Wiley, 1996; Vol. 4.

(3) Jang, Y. J.; Kim, K.; Tsay, O. G.; Atwood, D. A.; Churchill, D. G. Update 1 of: Destruction and Detection of Chemical Warfare Agents. Chem. Rev. 2015, 115, PR1-PR76.

(4) Black, R. M.; Read, R. W. Environmental and Biomedical Sample Analysis in Surpport of Allegations of Use of Chemical Warfare Agents. Toxin Rev. 2007, 26, 275-298.

(5) Yokoyama, K.; Araki, S.; Murata, K.; Nishikitani, M.; Okumura, T.; Ishimatsu, S.; Takasu, N. Chronic Neurobehavioral and Central and Autonomic Nervous System Effects of Tokyo Subway Sarin Poisoning. J. Physiol. (Paris) 1998, 92, 317-323.

(6) Morita, H.; Yanagisawa, N.; Nakajima, T.; Shimizu, M.; Hirabayashi, H.; Okudera, H.; Nohara, M.; Midorikawa, Y.; Mimura, S. Lancet 1995, 346, 290.

(7) Sellström, A.; Cairns, S.; Barbeschi, M. UN Mission to Investigate Allegations of Chemcial Weapons in the Syrian Arab Republic: Report on Allegations of the Use of Chemical Weapons in the Ghouta Area of Damascus on 21 August 2013; NY: United Nations: New York, 2013. (8) Rice, H.; Dalton, C. H.; Price, M. E.; Graham, S. J.; Green, A. C.; Jenner, J.; Groombridge, H. J.; Timperley, C. M. Toxicity and Medical Countermeasure Studies on the Organophophorus Nerve Agents VM and VX. Proc. R. Soc. London, Ser. A 2015, 471, 20140891.

(9) Taylor, D. E.; Runge, K.; Cory, M. G.; Burns, D. S.; Vasey, J. L.; Hearn, J. D.; Griffith, K.; Henley, M. V. Surface Binding of Organophosphates on Silica: Comparing Experiment and Theory. J. Phys. Chem. C 2013, 117, 2699-2708.

(10) Michalkova, A.; Gorb, L.; Ilchenko, M.; Zhikol, O. A.; Shishkin, O. V.; Leszczynski, J. Adsorption of Sarin and Soman on Dickite: $A n$ $A b$ Initio ONIOM Study. J. Phys. Chem. B 2004, 108, 1918-1930.

(11) Troya, D.; Edwards, A. C.; Morris, J. R. Theoretical Study of the Adsorption of Organophosphorous Compounds to Models of a Silica Surface. J. Phys. Chem. C 2013, 117, 14625-14634.

(12) Wilmsmeyer, A. R.; Gordon, W. O.; Davis, E. D.; Troya, D.; Mantooth, B. A.; Lalain, T. A.; Morris, J. R. Infrared Spectra and Binding Energies of Chemical Warfare Nerve Agent Simulants on the Surface of Amorphous Silica. J. Phys. Chem. C 2013, 117, 1568515697.
(13) Papas, B. N.; Petsalakis, I. D.; Theodorakopoulos, G.; Whitten, J. L. CI and DFT Studies of the Adsorption of the Nerve Agent Sarin on Surfaces. J. Phys. Chem. C 2014, 118, 23042-23048.

(14) Cuisset, A.; Mouret, G.; Pirali, O.; Roy, P.; Cazier, F.; Nouali, H.; Demaison, J. Gas-Phase Vibrational Spectroscopy and Ab Initio Study of Organophophorous Compounds: Discrimination between Species and Conformers. J. Phys. Chem. B 2008, 112, 12516-12525.

(15) Sharpe, S. W.; Johnson, T. J.; Chu, P. M.; Kleimeyer, J.; Rowland, B. Quantitative Infrared Spectra of Vapor Phase Chemical Agents. Chemical and Biological Sensing; Proceedings SPIE 5085; SPIE, 2003; Vol. 4, 10.1117/12.487073.

(16) Khan, M. A. S.; Kesharwani, M. K.; Bandyopadhyay, T.; Ganguly, B. Remarkable Effect of Hydroxylamine Anion towards the Solvolysis of Sarin: A DFT Study. J. Mol. Struct.: THEOCHEM 2010, 944, 132-136.

(17) Gershonov, E.; Columbus, I.; Zafrani, Y. Facile HydrolysisBased Chemical Destruction of the Warfare Agents VX, GB, and HD by Alumina-Supported Fluoride Reagents. J. Org. Chem. 2009, 74, 329-338.

(18) Guo, N.; Zhong, J.-Y.; Chen, S.-L.; Liu, J.-Q.; Min, Q.; Shi, R.-X. Experimental and Theoretical Studies of Hydrolysis of Nerve Agent Sarin by Binuclear Zinc Biomimetic Catalysts. Chem. Phys. 2015, 457, $70-77$.

(19) Kiddle, J. J.; Mezyk, S. P. Reductive Destruction of Chemical Warfare Agent Simulants in Water. J. Phys. Chem. B 2004, 108, 95689570.

(20) Zegers, E. J. P.; Fisher, E. M. Gas-Phase Pyrolysis of Diisopropyl Methylphosphonate. Combust. Flame 1998, 115, 230-240.

(21) Glaude, P. A.; Melius, C.; Pitz, W. J.; Westbrook, C. K. Detailed Chemical Kinetics Reaction Mechanisms for Incineration of Organophosphorus and Fluoroorganophosphorus Compounds. Proc. Combust. Inst. 2002, 29, 2469-2476.

(22) Ash, T.; Debnath, T.; Banu, T.; Das, A. K. Exploration of Unimolecular Gas-Phase Detoxication Pathways of Sarin and Soman: A Computational Study from the Perspective of Reaction Energetics and Kinetics. Chem. Res. Toxicol. 2016, 29, 1439-1457.

(23) Baer, T.; Hase, W. L. Unimolecular Reaction Dynamics Theory and Experiments; Oxford University Press, Inc.: New York, 1996.

(24) Greene, S. M.; Shan, X.; Clary, D. C. An Investigation of OneVersus Two-Dimensional Semiclassical Transition State Theory for $\mathrm{H}$ Atom Abstraction and Exchange Reactions. J. Chem. Phys. 2016, 144, 084113.

(25) Greene, S. M.; Shan, X.; Clary, D. C. Rate Constants of Chemical Reactions from Semiclassical Transition State Theory in Full and One Dimension. J. Chem. Phys. 2016, 144, 244116.

(26) Chuang, Y.-Y.; Truhlar, D. G. Statistical Thermodynamics of Bond Torsional Modes. J. Chem. Phys. 2000, 112, 1221-1228.

(27) Ellingson, B. A.; Lynch, V. A.; Mielke, S. L.; Truhlar, D. G. Statistical Thermodynamics of Bond Torsional Modes: Tests of Separable, Almost-Separable, and Improved Pitzer-Gwinn Approximations. J. Chem. Phys. 2006, 125, 084305.

(28) Zheng, J.; Truhlar, D. G. Kinetics of Hydrogen-Transfer Isomerizations of Butoxyl Radicals. Phys. Chem. Chem. Phys. 2010, 12, $7782-7793$.

(29) Zheng, J.; Yu, T.; Papajak, E.; Alecu, I. M.; Mielke, S. L.; Truhlar, D. G. Practical Methods for Including Torsional Anharmonicity in Thermochemical Calculations on Complex Molecules: The Internal-Coordinate Multi-Structural Approximation. Phys. Chem. Chem. Phys. 2011, 13, 10885-10907.

(30) Miller, W. H. Semi-Classical Theory for Non-Separable Systems: Construction of "Good" Action-Angle Variables for Reaction Rate Constants. Faraday Discuss. Chem. Soc. 1977, 62, 40-46.

(31) Miller, W. H. Recent Advances in Quantum Mechanical Reactive Scattering Theory, Including Comparison of Recent Experiments with Rigorous Calculations of State-to-State Cross Sections for the $\mathrm{H} / \mathrm{D}+\mathrm{H}_{2} \rightarrow \mathrm{H}_{2} / \mathrm{HD}+\mathrm{H}$ Reactions. Annu. Rev. Phys. Chem. 1990, $41,245-281$.

(32) Miller, W. H.; Hernandez, R.; Handy, N. C.; Jayatilaka, D.; Willetts, A. $A b$ Initio Calculation of Anharmonic Constants for a 
Transition State, with Application to Semiclassical Transition State Tunneling Probabilities. Chem. Phys. Lett. 1990, 172, 62-68.

(33) Cohen, M. J.; Handy, N. C.; Hernandez, R.; Miller, W. H. Cumulative Reaction Probabilities for $\mathrm{H}+\mathrm{H}_{2} \rightarrow \mathrm{H}_{2}+\mathrm{H}$ from a Knowledge of the Anharmonic Force Field. Chem. Phys. Lett. 1992, 192, 407-416.

(34) Hernandez, R.; Miller, W. H. Semiclassical Transition State Theory: A New Perspective. Chem. Phys. Lett. 1993, 214, 129-136.

(35) Nguyen, T. L.; Stanton, J. F.; Barker, J. R. Ab Initio Reaction Rate Constants Computed Using Semiclassical Transition-State Theory: $\mathrm{HO}+\mathrm{H}_{2} \rightarrow \mathrm{H}_{2} \mathrm{O}+\mathrm{H}$ and Isotopologues. J. Phys. Chem. A 2011, 115, 5118-5126.

(36) Barker, J. R.; Nguyen, T. L.; Stanton, J. F. Kinetic Isotope Effects for $\mathrm{Cl}+\mathrm{CH}_{4} \rightleftharpoons \mathrm{HCl}+\mathrm{CH}_{3}$ Calculated Using $\mathrm{Ab}$ Initio Semiclassical Transition State Theory. J. Phys. Chem. A 2012, 116, 6408-6419.

(37) Weston, R. E.; Nguyen, T. L.; Stanton, J. F.; Barker, J. R. HO + CO Reaction Rates and H/D Kinetic Isotope Effects: Master Equation Models with ab Initio SCTST Rate Constants. J. Phys. Chem. A 2013, $117,821-835$

(38) Greene, S. M.; Shan, X.; Clary, D. C. Reduced-Dimensionality Semiclassical Transition State Theory: Application to Hydrogen Atom Abstraction and Exchange Reactions of Hydrocarbons. J. Phys. Chem. A 2015, 119, 12015-12027.

(39) Stanton, J. F. Semiclassical Tranistion-State Theory Based on Fourth-Order Vibrational Perturbation Theory: The Symmetrical Eckart Barrier. J. Phys. Chem. Lett. 2016, 7, 2708-2713.

(40) Shiekh, B. A.; Kaur, D. The Role of Tortional Motion on the Properties of Propiolic Acid and Its H/D Isotopic Analogs: A Density Functional Study Using SCTST and a Full Anharmonic VPT2 Model. Chem. Phys. Lett. 2016, 646, 168-173.

(41) Shiekh, B. A.; Kaur, D.; Seth, B.; Mahajan, S. The TheoreticalCum-Statistical Approach for the Investigation of Reaction $\mathrm{NO}_{2}+\mathrm{O}-$ $\left({ }^{3} \mathrm{P}\right) \leftarrow \mathrm{NO}+\mathrm{O}_{2}$ Using SCTST and a Full Anharmonic VPT2 Model. Chem. Phys. Lett. 2016, 662, 244-249.

(42) Mills, I. M. In Molecular Spectroscopy: Modern Research; Mathews, C. W., Rao, K. N., Eds.; Academic Press: New York, 1972; pp Chapter 3.2, 115-140.

(43) Griffiths, D. J. Introduction to Quantum Mechanics, 2nd ed.; Pearson Education, Inc.: Upper Saddle River, NJ, 2005.

(44) Wagner, A. F. Improved Multidimensional Semiclassical Tunneling Theory. J. Phys. Chem. A 2013, 117, 13089-13100.

(45) Richardson, L. F.; Gaunt, J. A. The Deferred Approach to the Limit. Part I. Single Lattice. Part II. Interpenetrating Lattices. Philos. Trans. R. Soc., A 1927, 226, 299-361.

(46) Ridders, C. Accurate Computation of $\mathrm{F}^{\prime \prime}(\mathrm{x})$ and $\mathrm{F}^{\prime \prime}(\mathrm{x}) \mathrm{F}^{\prime \prime}(\mathrm{x})$. Adv. Eng. Software 1982, 4, 75-76.

(47) Press, W. H.; Teukolsky, S. A.; Vetterling, W. T.; Flannery, B. P. Numerical Recipes in C: The Art of Scientific Computing, 2nd ed.; Cambridge University Press: Cambridge, England, 1992.

(48) Miller, W. H. Semiclassical Limit of Quantum Mechanical Transition State Theory for Nonseparable Systems. J. Chem. Phys. 1975, 62, 1899.

(49) Wang, F.; Landau, D. P. Efficient, Multiple-Range Random Walk Algorithm to Calculate the Density of States. Phys. Rev. Lett. 2001, 86, 2050-2053.

(50) Wang, F.; Landau, D. P. Determining the Density of States for Classical Statistical Models: A Random Walk Algorithm to Produce a Flat Histogram. Phys. Rev. E: Stat. Phys., Plasmas, Fluids, Relat. Interdiscip. Top. 2001, 64, 056101.

(51) Basire, M.; Parneix, P.; Calvo, F. Quantum Anharmonic Densities of States Using the Wang-Landau Method. J. Chem. Phys. 2008, 129, 081101.

(52) Nguyen, T. L.; Barker, J. R. Sums and Densities of Fully Coupled Anharmonic Vibrational States: A Comparison of Three Practical Methods. J. Phys. Chem. A 2010, 114, 3718-3730.

(53) Miller, W. H. Tunneling Corrections to Unimolecular Rate Constants, with Application to Formaldehyde. J. Am. Chem. Soc. 1979, 101, 6810-6814.
(54) Stein, S. E.; Rabinovitch, B. S. Accurate Evaluation of Internal Energy Level Sums and Densities Including Anharmnoic Oscillators and Hindered Rotors. J. Chem. Phys. 1973, 58, 2438-2445.

(55) Gaussian 09, Revision E.01; Gaussian, Inc.: Wallingford, CT, 2009.

(56) Dunning, T. H., Jr. Gaussian Basis Sets for Use in Correlated Molecular Calculations. I. The Atoms Boron Through Neon and Hydrogen. J. Chem. Phys. 1989, 90, 1007-1023.

(57) Dunning, T. H., Jr.; Peterson, K. A.; Wilson, A. K. Gaussian Basis Sets for Use in Correlated Molecular Calculations. X. The Atoms Aluminum Through Argon Revisited. J. Chem. Phys. 2001, 114, 92449253.

(58) Woon, D. E.; Dunning, T. H. Gaussian Basis Sets for Use in Correlated Molecular Calculations. III. The Atoms Aluminum through Argon. J. Chem. Phys. 1993, 98, 1358.

(59) Papajak, E.; Zheng, J.; Xu, X.; Leverentz, H. R; Truhlar, D. G. Perspectives on Basis Sets Beautiful: Seasonal Plantings of Diffuse Basis Functions. J. Chem. Theory Comput. 2011, 7, 3027.

(60) Halkier, A.; Helgaker, T.; Jørgensen, P.; Klopper, W.; Koch, H.; Olsen, J.; Wilson, A. K. Basis-Set Convergence in Correlated Calculations on $\mathrm{Ne}, \mathrm{N}_{2}$, and $\mathrm{H}_{2} \mathrm{O}$. Chem. Phys. Lett. 1998, 286, $243-252$.

(61) Remmert, S. M.; Banks, S. T.; Harvey, J. N.; Orr-Ewing, A. J.; Clary, D. C. Reduced Dimensionality Spin-Orbit Dynamics of $\mathrm{CH}_{3}+$ $\mathrm{HCl} \rightleftharpoons \mathrm{CH}_{4}+\mathrm{Cl}$ on $\mathrm{Ab}$ Initio Surfaces. J. Chem. Phys. 2011, 134, 204311.

(62) von Horsten, H. F.; Banks, S. T.; Clary, D. C. An Efficient Route to Thermal Rate Constants in Reduced Dimensional Quantum Scattering Simulations: Applications to the Abstraction of Hydrogen from Alkanes. J. Chem. Phys. 2011, 135, 094311.

(63) Shan, X.; Clary, D. C. Quantum Effects in the Abstraction Reaction by $\mathrm{H}$ Atoms of Primary and Secondary Hydrogens in $\mathrm{n}$ $\mathrm{C}_{4} \mathrm{H}_{10}$ : A Test of a New Potential Energy Surface Construction Method. Phys. Chem. Chem. Phys. 2013, 15, 1222-1231.

(64) Remmert, S. M.; Banks, S. T.; Clary, D. C. Reduced Dimensionality Quantum Dynamics of $\mathrm{CH}_{3}+\mathrm{CH}_{4} \rightarrow \mathrm{CH}_{4}+\mathrm{CH}_{3}$ : Symmetric Hydrogen Exchange on an $\mathrm{Ab}$ Initio Potential. J. Phys. Chem. A 2009, 113, 4255-4264.

(65) Pitzer, K. S.; Gwinn, W. D. Energy Levels and Thermodynamic Functions for Molecules with Internal Rotation I. Rigid Frame with Attached Tops. J. Chem. Phys. 1942, 10, 428-440.

(66) Pitzer, K. S. Energy Levels and Thermodynamic Functions for Molecules with Internal Rotation II. Unsymmetrical Tops Attached to a Rigid Frame. J. Chem. Phys. 1946, 14, 239-243.

(67) Kilpatrick, J. E.; Pitzer, K. S. Energy Levels and Thermodynamic Functions for Molecules with Internal Rotation III. Compound Rotation. J. Chem. Phys. 1949, 17, 1064-1075.

(68) Barone, V. Anharmonic Vibrational Properties by a Fully Automated Second-Order Perturbative Approach. J. Chem. Phys. 2005, $122,014108$.

(69) Hoy, A.; Mills, I.; Strey, G. Anharmonic Force Constant Calculations. Mol. Phys. 1972, 24, 1265-1290.

(70) Khairutdinov, R.; Zamaraev, K. I.; Zhadanov, V. P. In Electron Tunneling in Chemistry; Compton, R. G., Ed.; Comprehensive Chemical Kinetics; Elsevier: Amsterdam, 1989; Vol. 30; pp 69-110.

(71) Timperley, C. M. Best Synthetic Methods: Organophosphorus(V) Chemistry; Elsevier: Oxford, UK, 2015. 